\title{
National Nanotechnology Initiative to Advance Broad Societal Goals
}

Nanoscale science and engineering are providing unprecedented understanding and control over the basic building blocks of matter, leading to increased coherence in knowledge, technology, and education. The main reason for developing nanotechnology is to advance broad societal goals, such as improved comprehension of nature, increased productivity, better healthcare, and extended limits of sustainable development and human potential. In the United States, the National Nanotechnology Initiative (NNI) was created for nanotechnology research and development (R\&D). It is a visionary program that coordinates 17 departments and independent agencies, forming an interagency group, with a total budget request of $\$ 774$ million in fiscal year 2003 and a request of $\$ 849$ million for fiscal year 2004 (details on www.nano.gov and www.nsf. gov/nano).

Nanotechnology R\&D investment by governments worldwide increased six-fold in the last six years between 1997 and 2003, from $\$ 432$ million to about $\$ 2.9$ billion. At least 35 countries have initiated national activities in this field, partially stimulated by the NNI vision and plans. Scientists have opened a broad net that does not leave any major research area untouched in the physical, biological, materials, and engineering sciences. Industry has gained confidence that nanotechnology will bring competitive advantages to both traditional and emerging fields, and significant growth is noted in small businesses, large companies, and venture funding. The annual global impact of products where nanotechnology will play a key role has been estimated to exceed $\$ 1$ trillion by 2015 and would require about 2 million nanotechnology workers.

On behalf of the interagency group, I proposed NNI on March 11, 1999, at the White House's Office of Science and Technology Policy (OSTP), with support from Neil Lane, then Assistant to the President for Science and Technology, and Tom Kalil, then Economic Advisor to the President. The initiative was announced by the White House on January 21, 2000. As a result, OSTP's National Science and Technology Council Subcommittee on Nanoscale Science, Engineering and Technology (NSET) was established in August 2000 to implement NNI. One month later, in September, the report Societal Implications of Nanoscience and Nanotechnology was prepared and its recommendations were reflected in the following National Science Foundation (NSF) program announcements and operation of the National Nanotechnology Coordination Office.

The NNI investment began in October 2000 with the following strategies: (a) focus on fundamental research ("horizontal" interdisciplinary knowledge creation with same principles, phenomena, tools, and structure architectures) combined with transition to technological innovation ("vertical" development from basic concepts to applications); (b) long-term vision as part of a coherent science and technology endeavor; (c) preparation of a diverse nanotechnology workforce; (d) policy of inclusion and partnerships, including promoting interdisciplinary research and interagency collaboration; and (e) attention to broad societal goals.

"Nanotechnology has the long-term potential to bring revolutionary changes in society and harmonize international efforts toward a higher purpose ..."

In the first two years of the initiative (2001-2002), progress was faster than expected, shortening the time expected to reach commercial prototypes in key relevant areas. Currently, nanostructured materials, nanoelectronics, catalysts, and pharmaceuticals are moving from fundamental discoveries to technological innovation. Furthermore, this year the initiative is exploring new areas in nanomedicine, energy conversion, food and agriculture, realistic simulations at the nanoscale, molecular architectures, environmental implications, and converging technologies from the nanoscale level.

Research on societal and educational implications will increase in importance as novel nanostructures are discovered, new nanotechnology products and services reach the market, and interdisciplinary research groups are established to study them. The NNI annual investment in research with societal and educational implications is estimated at about \$30 million (of which NSF awards about \$23 million). The annual investment in nanoscale research with relevance to environment is about $\$ 50$ million (of which NSF awards about \$30 million and the Environmental Protection Agency [EPA] awards about $\$ 6$ million). The total of about $\$ 80$ million is approximately $10 \%$ of the NNI budget in fiscal year 2003. The NSF's Nanotech- nology Undergraduate Education program has made about 35 awards in fiscal year 2003, and nanotechnology K-12 education is planned as a new focus in fiscal year 2004 .

A complementary and flexible infrastructure is being developed for 2004 by participating agencies. The NSF will run two user networks (the National Nanotechnology Infrastructure Network and the Network for Computational Nanotechnology) and eight Nanoscale Science and Engineering Centers and will continue support for 13 Materials Research Science and Engineering Centers with research at the nanoscale level. The Department of Energy (DOE) has established five largescale user facilities (the Nanoscale Science Research Centers). The National Aeronautics and Space Administration (NASA) has established four nanobio-information research centers; the Department of Defense, three centers; and the National Institutes of Health, several visualization and instrumentation centers.

$\mathrm{NNI}$ is operated with the same rigor as a scientific project, beginning with a longterm vision plan developed in 1999 (Nanotechnology Research Directions; see the Web site www.nano.gov). The National Research Council reviewed NNI in 2002, Small Wonders, Endless Frontiers, and made a series of recommendations, such as increasing R\&D investment on nanobiosystems and societal implications. The long-term vision for NNI will be updated in the first half of 2004 in the publication Nanotechnology Research Directions (II). For this purpose, several workshops on key areas of the initiative have been organized this year to provide long-term vision plans for the respective areas. These contributions will be integrated in the NNI strategic plan. The key areas of the workshops are materials, nanobiotechnology and medicine, nanoelectronics, bio-chemicalradioactive-explosive detection and protection, environment, agriculture and food systems, energy conversion and storage, and societal implications. The interagency vision-setting workshop on materials will be held in June 2003 at NSF (organizer Hugh M. Van Horn), and will examine how to take the field beyond conventional lithography, equilibrium materials, classical (binary logic) materials, and virtual materials.

The Bush Administration has provided strong support to nanotechnology. This year, the President's Council of Advisors on Science and Technology is undertaking a study of NNI by a panel co-chaired by John Marburger III and Floyd Kvamme. 
The council will use three task forces as well as the NSET Subcommittee to evaluate various topical areas.

Two draft bills for nanotechnology submitted to the current Congress address the need for coherent, multiyear planning with increased interdisciplinarity and interagency coordination. The Senate draft Bill S189, "21st Century Nanotechnology R\&D Act," recommends a five-year national nanotechnology program. It was introduced by a group of senators led by Ron Wyden (D-Ore.) and George Allen (R-Va.). The bill recently passed by a vote of 405 to 19 in the House of Representatives, H.R.766 "Nanotechnology Research and Development Act of 2003," was introduced by a group of representatives led by Sherwood Boehlert (R-N.Y.). It authorizes funding at NSF of $\$ 350$ million in fiscal year 2004, \$385 million in fiscal year 2005, and \$424 million in fiscal year 2006. The bill also authorizes lesser amounts for
DOE, NASA, EPA, and the National Institute of Standards and Technology. Societal goals and R\&D were discussed at each of the previous Congressional nanotechnology hearings, including one on March 19, but a special hearing on this topic was held on April 9, 2003, by the House Committee on Science. It suggested the need to increase funding in this area and to involve social scientists from the beginning in large NNI projects. A joint Senate-House nanotechnology bill is expected to be passed by the beginning of summer 2003.

Nanotechnology has the long-term potential to bring revolutionary changes in society and harmonize international efforts toward a higher purpose than just advancing a single field of science and technology or a single geographical region. A global strategy guided by broad societal goals is envisioned. The material unity of nature and corresponding scientific convergence at the nanoscale level should be reflected in a coherent plan for the R\&D nanotechnology programs. As the annual NNI R\&D budget approaches $\$ 1$ billion and industry is soon expected to exceed the government $R \& D$ investments, higher expectations of nanotechnology products and other societal benefits are raised in both the short and long term, and concerns about unexpected societal implications need to be answered to the public's satisfaction.

M.C. Roco

M.C. Roco chairs the U.S. National Science and Technology Council's (NSTC) Subcommittee on Nanoscale Science, Engineering and Technology (NSET), and he is Senior Advisor for Nanotechnology in the National Science Foundation. This article represents the views of the author and not necessarily those of the National Science Foundation and NSTC/NSET.

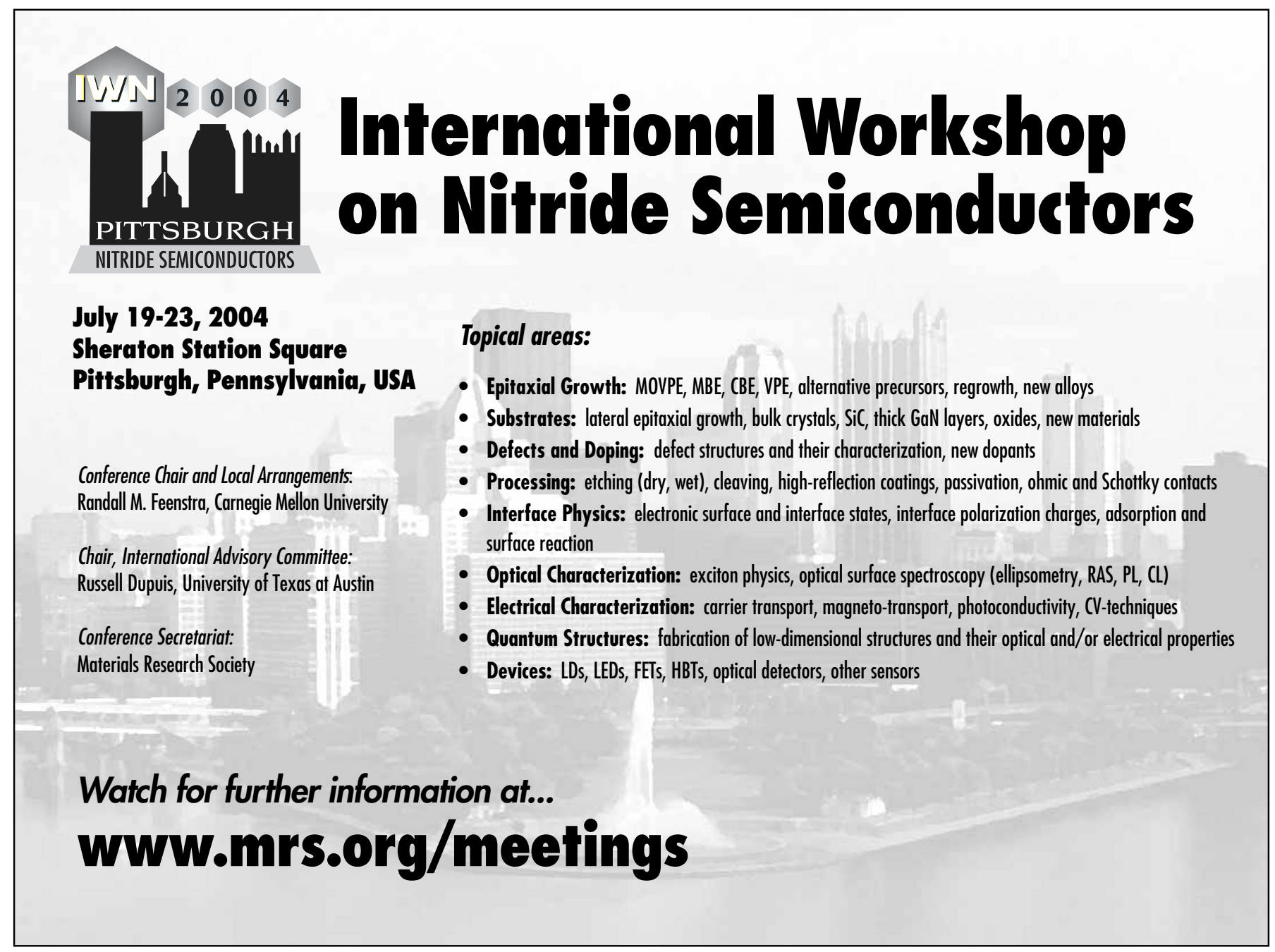

